\title{
Prevalence and awareness of anabolic androgenic steroid use among male body builders in Jazan, Saudi Arabia
}

\author{
Ahmed Bahri ${ }^{1}$, Mohamed Salih Mahfouz ${ }^{1 *}$, Nasser Mohammed Marran ${ }^{2}$, Yahya \\ Hadi Dighriri ${ }^{2}$, Hatem Saeed Alessa ${ }^{2}$, Moneer Ogiby Khwaji ${ }^{2}$ and Syed \\ Mahmood Zafar ${ }^{1}$ \\ ${ }^{1}$ Department of Community Medicine, ${ }^{2}$ Faculty of Medicine, Jazan University, Jazan, Kingdom of Saudi Arabia \\ *For correspondence: Email: mm.mahfouz@gmail.com; Tel: 0096656232711
}

Sent for review: 18 November 2016

Revised accepted: 9 May 2017

\begin{abstract}
Purpose: To examine the prevalence and awareness of anabolic-androgenic steroid (AAS) use among male bodybuilders visiting gyms in Jazan region, Saudi Arabia.

Methods: A cross-sectional survey was conducted among 500 male bodybuilders visiting gyms in the Jazan region of Saudi Arabia. Information on demographics, as well as the use of AAS, was included in a self-administered questionnaire.

Results: The prevalence of AAS in Jazan was $31.0 \%$ (95 \% Cl, 26.9 - 49.6), and it was higher among those in the 30 - 34 years $45.3 \%(95 \% \mathrm{Cl}, 36.9$ - 54.0). Its prevalence was also significantly higher among athletes who received higher education $37.4 \%$ (95 \% Cl, 31.8 - 43.4). The most common types of AAS used are Deca-Durabolin (57.6\%) and testosterone (52\%). Thirty percent of the participants who used AAS suffered from depression and aggressive behavior while $18 \%$ of them were hypertensive. The participants were not well aware of the adverse effects of anabolic steroids use.

Conclusion: The prevalence of the anabolic steroids is high among bodybuilding males visiting gyms in Jazan region, Saudi Arabia. Health educational programs are required to increase the awareness about the side effects of anabolic steroids among bodybuilders.
\end{abstract}

Keywords: Anabolic steroids, Bodybuilders, Deca-durabolin, Testosterone

Tropical Journal of Pharmaceutical Research is indexed by Science Citation Index (SciSearch), Scopus, International Pharmaceutical Abstract, Chemical Abstracts, Embase, Index Copernicus, EBSCO, African Index Medicus, JournalSeek, Journal Citation Reports/Science Edition, Directory of Open Access Journals (DOAJ), African Journal Online, Bioline International, Open-J-Gate and Pharmacy Abstracts

\section{INTRODUCTION}

Anabolic-androgenic steroids (AAS) are a type of synthetic steroid hormones related to the hormone testosterone [1,2]. These drugs are available by prescription and used to treat cases caused by an abnormal low production of testosterone, such as delayed puberty and impotence [1].

Serious side effects are noted among users of anabolic steroids. These include increase aggressiveness, euphoria, diminished fatigue, increased libido, and mood swings [3]. The side effects also comprise high blood pressure, liver tumors and cancers, fluid retention, and jaundice [1]. Other side effects include severe acne, kidney tumors and tremors [4]. In men, AAS can even cause shrinking of testicles, development of breasts and prostate cancers, baldness, reduced sperm count, and infertility [4-6].

Hall and Hall (2005), in their review, suggested that anabolic steroid abuse has become a major problem in the United States, with more than 1 million individuals abusing these drugs [7]. Another study conducted among health club users in the South Wales area revealed that AAS 
use is prevalent (70 \%) among recreational gym users [8]. Studies regarding the prevalence of AAS use among adolescents reported lifetime prevalence ranging from $1 \%$ to $5 \%$ [9].

In the Middle East, the number of gym users taking anabolic steroids is steadily increasing. Recent studies in Jordan found that $26 \%$ of bodybuilders reportedly used anabolic steroids [10]. The use of anabolic steroids among gym users in United Arab Emirates was estimated at $22 \%$ [2] while AAS use among Iranian youths training to be bodybuilders was about $13 \%$ [11]. In Kuwait, $22.7 \%$ of the general population and $4.2 \%$ of college students are AAS users [12].

Evidence suggests that an increasing number of deaths of athletes in the age group of $20-30$ years is due to heart diseases resulting from AAS use [13]. AAS are toxic to the cardiac tissue and leads to cardiomyopathy with impaired systolic and diastolic functions [14,15]. The use of AAS also leads to increased LDL and decreased HDL in the blood, which represents a great risk for coronary heart disease [4,16-18]. There are still a limited number of studies suggesting AAS-induced atherosclerosis [19,20].

Exogenous AAS use disturbs the hypothalamicpituitary-testicular (HPT) axis in males [21]. They become hypogonadal when they stop using anabolic steroids abruptly after prolonged use [21]. Active oral AAS can cause hepatotoxicity and hepatic neoplasms [22] Prostate hypertrophy with an increased risk of prostate cancer can also occur with prolonged use of AAS [23-25]. Other resulting psychiatric disorders include psychosis, hypomania, and severe depression [24-26].

It should be noted that no previous study was conducted on the use of anabolic steroids among male bodybuilders using gym facilities in Jazan, Saudi Arabia. The main objective of this paper is to estimate the prevalence of anabolic steroid and its awareness among male bodybuilders visiting gyms in the Jazan region.

\section{METHODS}

\section{Study design and setting}

An observational cross-sectional survey was conducted in the Jazan region. Jazan (or Gizan) region lies in the southwest corner of Saudi Arabia, north of the border with Yemen; the region is sub-divided into 14 governorates. The region is one of the 13 regions comprising the Kingdom of Saudi Arabia and has a population of approximately 1.5 million.

\section{Sampling procedure}

Using the statistical formula for cross-sectional study design, the sample size for this study was estimated to be 500 participants. The calculation was based on the prevalence of AAS = 50\%, 95 $\%$ confidence interval $(\mathrm{Cl})$, error below $5 \%$, and a non-response rate of $25 \%$. The research team excluded the governorates that did not have any gym facilities. After exclusion, we ended up with six governorates. We, then, randomly selected one gym from each selected governorate. The selected governorates were Sabya, Samtah, Abu Arish, Jazan, Baish, and Ahad AL-Masaraihah. The final sample size was distributed among the selected gyms proportionate to the actual bodybuilders' size in each gym. In each selected gym, the study participants were identified using systematic random sampling.

\section{Data collection}

A self-administered questionnaire was used for data collection. The questionnaire was designed after consulting a number of previous studies conducted in the same domain $[2,12]$. The final version of the questionnaire involved approximately 50 multiple-choice questions. The questions included sections on background characteristics of study participants, types of AAS used, reported side effects, and questions concerning knowledge and attitude in relation to AAS use.

\section{Statistical analysis}

The statistical analysis was performed using SPSS ver. 20.0 (SPSS Inc. Chicago, IL, USA) software. The prevalence of anabolic steroid use among the study subjects was calculated using $95 \%$ confidence intervals $(\mathrm{Cl})$. The Chi-square test/ Fisher's exact test was used to evaluate the prevalence of use among the different subgroups. The $p$ value less than 0.05 was used to indicate statistical significance.

\section{Ethical considerations}

Ethical approval for this study was obtained from the College of Medicine, Jazan University, Jazan. Saudi Arabia (approval no. CLC 432-2015/2016 Module). Participants signed the study consent before answering the survey questionnaire. It was made clear to all participants that they had the right to not participate in the study or withdraw from the survey at any time if they wished to do so. Also, subjects' privacy was ensured at all study stages. The survey data was kept confidential and utilized for study purposes only and the whole ethics procedures is 
conducted in accordance with the International ethical guidelines for biomedical research involving human subjects [27].

\section{RESULTS}

A total of 500 questionnaires were distributed among male bodybuilders visiting gyms. A total of 465 questionnaires were included in the final analysis (93\%), and the rest of the questionnaires $(7 \%)$ were excluded from the study due to non-response. Table 1 shows the demographic characteristics of the study population. According to the table, more than 50 $\%$ of the study participants received higher education. The majority of male bodybuilders were between 20 - 34 years, which represented approximately $80 \%$ of the total. About $42 \%$ of the samples were students, and $45 \%$ were employed. Forty percent of the samples have a monthly income between $\$ 261$ and $\$ 1333$, and about $25 \%$ drew income less than \$260.

Table 1: Background characteristics of the study population $(n=465)$

\begin{tabular}{lcc}
\hline Characteristic & $\mathbf{N}$ & $\%$ \\
\hline $\begin{array}{l}\text { Level of education } \\
\text { Basic education }\end{array}$ & 205 & 44.1 \\
Higher education & 260 & 55.9 \\
Age group (years) & & \\
15-19 & 68 & 14.6 \\
$20-24$ & 140 & 30.1 \\
$25-29$ & 96 & 20.6 \\
$30-34$ & 128 & 28 \\
$>34$ & 33 & 7.1 \\
Occupation & & \\
Unemployed & 60 & 12.9 \\
Student & 194 & 41.7 \\
Employed & 211 & 45.4 \\
Monthly income (\$) & & \\
$\quad<260$ & 118 & 25.4 \\
$261-1333$ & 185 & 39.8 \\
1334 - 2765 & 89 & 21.1 \\
$>2766$ & 61 & 13.1 \\
\hline
\end{tabular}

Table 3 shows that AAS use is significantly higher among male bodybuilders (38.7 \%) compared with other sports. AAS use was very high $(46.7 \%)$ and significantly different among participants who used gym for a period of one to less than two years. AAS use is positively associated with the duration of gym use per hour ( $p$ value 0.001 ). AAS use is also positively associated with frequency of gym use per week but with no significant association ( $p$ value $0.302)$.
According to Table 4, the most common types of AAS used are Deca-Durabolin (57.6\%) and testosterone (52\%). Bodybuilders usually use AAS as a course for a predefined period of time. The course usually has more than one type of steroid as mentioned in Table 4. The same table illustrates the route of administration of AAS. Thirty-eight percent of the users use needle or injections, $27 \%$ use oral steroids while $35 \%$ use both needles and oral steroids. Twenty-seven percent of the participants who used AAS reported depression and aggressive behavior while $36 \%$ of them demonstrated hypertension. More than 35 percent of them had been using steroids for less than a year while $15.3 \%$ of them had been using steroids for two years and more.

According to Figure 1,56\% of the participants agreed that anabolic steroids can cause side effects while $58.6 \%$ of them believed that AAS use has a beneficial effect on them. Sixty-one percent of the participants had no knowledge about the sexual problems arising out of AAS use. Thirty-one percent of the participants knew that AAS can increase blood pressure while 47 $\%$ of them knew about the behavioral changes due to AAS abuse.

\section{DISCUSSION}

This study shows the prevalence of AAS use among male bodybuilders visiting gyms in the Jazan region. The prevalence of AAS users in Jazan region was as high as $31 \%$. The comparison of our findings with the studies conducted in different countries reveals a shocking conclusion: the abuse of AAS in the Jazan region was more than double the prevalence of AAS use among Iranian bodybuilders (13\%) [11]. Also, AAS use was much higher than that reported in similar studies conducted in Kuwait $(22 \%)$ and United Arab of Emirates (22\%) [2,12]. The prevalence of AAS use among gym users in Jazan region was very high. A possible explanation for this is the competition among gym users to build muscles over a short span of time. Another reason could be the absence of awareness programs among the gym users.

The highest prevalence (45.3\%) of AAS usage was among the 30-34 age. This result is different from what was reported in Kuwait and Middle East and North Africa (MENA) region studies [12]. The highest prevalence of AAS use in Kuwait was among the age group of 19-25 years was $(46.8 \%)$, which was similar to that reported in the MENA region. 
Table 2: Prevalence of anabolic steroid use according to selected characteristic, Jazan, KSA ( $n=465)$

\begin{tabular}{ccccc}
\hline Characteristic & Users/Total & Prevalence & $\mathbf{9 5 \%} \mathbf{C l}$ & $\boldsymbol{P}$-value \\
\hline Level of education & & & & \\
Basic education & $46 / 203$ & 22.7 & $17.4-28.9$ & 0.001 \\
Higher education & $98 / 262$ & 37.4 & $31.8-43.4$ & \\
Age group (years) & & & & \\
$15-19$ & $12 / 68$ & 17.6 & $10.4-28.4$ & \\
$20-24$ & $30 / 140$ & 21.4 & $15.5-29.0$ & \\
$25-29$ & $37 / 96$ & 38.5 & $29.4-48.6$ & \\
$30-34$ & $58 / 128$ & 45.3 & $36.9-54.0$ & \\
$>34$ & $7 / 33$ & 21.2 & $10.7-37.9$ & $<0.001$ \\
Occupation & & & & \\
Unemployed & $22 / 60$ & 36.7 & $25.6-49.4$ & \\
Student & $45 / 194$ & 23.2 & $17.8-29.6$ & \\
Employed & $77 / 211$ & 36.5 & $30.3-43.2$ & 0.009 \\
Monthly income (\$) 260 & & & & \\
261 - 1333 & $30 / 118$ & 25.4 & $18.4-34.0$ & \\
1334 - 2765 & $49 / 185$ & 26.5 & $20.7-33.3$ & \\
$>2766$ & $42 / 100$ & 42.0 & $32.8-51.8$ & \\
Overall prevalence & $23 / 62$ & 37.1 & $26.1-49.6$ & 0.028 \\
\hline
\end{tabular}

Table 3: Distribution of AAS users and non-users according to some selected characteristic $(n=465)$

\begin{tabular}{|c|c|c|c|}
\hline \multirow[t]{2}{*}{ Variable } & \multicolumn{2}{|c|}{ AAS use } & \multirow[t]{2}{*}{$P$-value } \\
\hline & Yes, N(\%) & No, N(\%) & \\
\hline \multicolumn{4}{|l|}{ Type of exercise } \\
\hline Bodybuilding & $138(38.7)$ & $219(61.3)$ & \multirow{4}{*}{$<0.001$} \\
\hline Swimming & 0 & $10(100)$ & \\
\hline Fitness & $3(4.2)$ & $69(95.8)$ & \\
\hline Martial art & $3(11.5)$ & $23(88.5)$ & \\
\hline \multicolumn{4}{|l|}{ Gym use duration } \\
\hline$<6$ months & $6(5.6)$ & $101(94.4)$ & \multirow{4}{*}{$<0.001$} \\
\hline 6 to $<12$ months & $41(31.3)$ & $90(68.7)$ & \\
\hline 12 to 24 months & $57(46.7)$ & $65(53.3)$ & \\
\hline$\geq 24$ months & $40(38.5)$ & $64(61.5)$ & \\
\hline \multicolumn{4}{|c|}{ Duration of daily gym use } \\
\hline$<1 \mathrm{~h}$ & $76(26.9)$ & $207(73.1)$ & \multirow{3}{*}{0.001} \\
\hline 1 to $<2 h$ & $40(31.5)$ & $87(68.5)$ & \\
\hline$\geq 2 \mathrm{~h}$ & $28(52.8)$ & $25(47.2)$ & \\
\hline \multicolumn{4}{|c|}{ No of visits to gym/week } \\
\hline Once & $4(17.4)$ & $19(82.6)$ & \multirow{5}{*}{0.302} \\
\hline Twice & $2(22.2)$ & $7(77.8)$ & \\
\hline Three times & $16(23.9)$ & $51(76.1)$ & \\
\hline Four times & $52(32.9)$ & $106(67.1)$ & \\
\hline Five times and more & $70(33.7)$ & $138(66.3)$ & \\
\hline
\end{tabular}

Most of our study participants had information about AAS benefits (e.g. increasing muscle size and endurance), but their knowledge about the side effects of AAS was very low. This explains the lack of public awareness about the risk of AAS use. Interestingly, our study revealed that there is a significant association between AAS use and high level of education. The prevalence of AAS use was higher among bodybuilders who received higher education, which means that awareness is independent of AAS use. Other studies concluded that spreading awareness about the side effects of AAS may not be the only effective strategy for limiting their abuse [12].

\section{Limitations of the study}

The study had few limitations. First, the research team did not ask for more details about the content and dose of AAS. Second, the study utilized a self-administered questionnaire to collect data on AAS use and their side effects. No other confirmation method was used to document AAS use among study participants. Finally, the study was based on a cross-sectional study design, which is not appropriate for assessing associations, and the causal relationships between the variables cannot be established properly. 
Table 4: Pattern of AAS use among male bodybuilders visiting gyms and reported side effects

\begin{tabular}{|c|c|c|}
\hline Characteristic & $\begin{array}{l}\text { No. of } \\
\text { users }\end{array}$ & $(\%)^{*}$ \\
\hline \multicolumn{3}{|l|}{ Brand (generic name) } \\
\hline Testosterone (Enanthate) & 54 & 37.5 \\
\hline Anvar (oxandrolone) & 38 & 26.3 \\
\hline Winstrol (stanozolol) & 25 & 17.3 \\
\hline Testosterone (Varies) & 75 & 52.0 \\
\hline Deca-Durabolin (drolonedecanoate) & 83 & 57.6 \\
\hline Primobolan & 24 & 16.6 \\
\hline \multicolumn{3}{|l|}{ Route of administration } \\
\hline Needle or injections & 55 & 38.2 \\
\hline Use oral steroids & 39 & 27.1 \\
\hline Both needles and oral steroids. & 50 & 34.7 \\
\hline \multicolumn{3}{|l|}{ Side effects } \\
\hline Any side effect & 46 & 31.9 \\
\hline depression and aggressive & 39 & 27.1 \\
\hline hypertension & 25 & 36.0 \\
\hline \multicolumn{3}{|l|}{ Duration of use } \\
\hline Less than 6 months & 38 & 26.4 \\
\hline 6 months to less than one & 51 & 35.4 \\
\hline One year to less than two & 33 & 22.9 \\
\hline Two years and more & 22 & 15.3 \\
\hline
\end{tabular}

\section{Conflict of Interest}

No conflict of interest associated with this work.

\section{Contribution of Authors}

The authors declare that this work was done by the authors named in this article and all liabilities pertaining to claims relating to the content of this article will be borne by them.

\section{Open Access}

This is an Open Access article that uses a funding model which does not charge readers or their institutions for access and distributed under the terms of the Creative Commons Attribution License (http://creativecommons.org/licenses/by/ 4.0) and the Budapest Open Access Initiative (http://www.budapestopenaccessinitiative.org/rea d), which permit unrestricted use, distribution, and reproduction in any medium, provided the original work is properly credited.

\section{REFERENCES}

1. Hartgens $F$, Kuipers $H$. Effects of androgenic-anabolic steroids in athletes. Sports Med 2004; 34(8):513-54.

2. Al-Falasi O, Al-Dahmani K, Al-Eisaei K, Al-Ameri S, AlMaskari F, Nagelkerke N, Schneider J. Knowledge, Attitude and Practice of Anabolic Steroids Use Among Gym Users in Al-Ain District, United Arab Emirates. Open Sports Med. 2008; 2:75-81.

3. Choi PY, Parrott AC, Cowan D. High-dose anabolic steroids in strength athletes: Effects upon hostility and aggression. Hum Psychopharmacol Clin Exp. 1990; 5(4):349-56.

4. Hartgens $F$, Kuipers $H$. Effects of androgenic-anabolic steroids in athletes. Sports Med. 2004; 34(8):513-54.

5. American Academy of Pediatrics. Adolescents and anabolic steroids: a subject review. J Pediatr. 1997; 99(6):1-0.

6. Mhillaj E, Morgese MG, Tucci P, Bove M, Schiavone S, Trabace L. Effects of anabolic-androgens on brain reward function. Front Neurosci. 2015; 9.

7. Hall RC, Hall RC. Abuse of supraphysiologic doses of anabolic steroids. South Med J. 2005; 98(5):550-5.

8. Baker JS, Graham MR, Davies B. Steroid and prescription medicine abuse in the health and fitness community: A regional study. Eur J Intern Med. 2006; 17(7):479-84.

9. Thiblin I, Petersson A. Pharmacoepidemiology of anabolic androgenic steroids: a review. Fundam Clin Pharmacol. 2005; 19(1):27-44.

10. Tahtamouni LH, Mustafa NH, Alfaouri AA, Hassan IM, Abdalla MY, Yasin SR. Prevalence and risk factors for anabolic-androgenic steroid abuse among Jordanian 
collegiate students and athletes. Eur J Public Health. 2008; 18(6):661-5.

11. Nojoomi M, Behravan V. Study of anabolic steroids and the awareness of their complications in bodybuilding athletes in Karaj (2003). Razi Journal of Medical Sciences. 2005 Mar 15;11(44):1057-63.

12. Alsaeed I, Alabkal JR. Usage and perceptions of anabolic-androgenic steroids among male fitness centre attendees in Kuwait-a cross-sectional study. Subst Abuse Treat Prev Policy. 2015 Aug 22;10(1):1.

13. Kanayama G, Kean J, Hudson JI, Pope HG. Cognitive deficits in long-term anabolic-androgenic steroid users. Drug Alcohol Depend. 2013; 130(1):208-14.

14. D'Andrea A, Caso P, Salerno G, Scarafile R, De Corato G, Mita C, Di Salvo G, Severino S, Cuomo S, Liccardo $B$, Esposito N. Left ventricular early myocardial dysfunction after chronic misuse of anabolic androgenic steroids: a Doppler myocardial and strain imaging analysis. Br J Sports Med. 2007; 41(3):149-55.

15. Kasikcioglu E, Oflaz H, Umman B, Bugra Z. Androgenic anabolic steroids also impair right ventricular function. Int J Cardiol. 2009; 134(1):123-5.

16. Glazer G. Atherogenic effects of anabolic steroids on serum lipid levels: a literature review. Arch Intern Med. 1991; 151(10):1925-33

17. Kouri EM, Pope Jr HG, Oliva PS. Changes in lipoproteinlipid levels in normal men following administration of increasing doses of testosterone cypionate. Clin J Sport Med. 1996; 6(3):152-7.

18. Grundy SM, Cleeman JI, Merz CN, Brewer HB, Clark $L T$, Hunninghake DB, Pasternak RC, Smith SC, Stone NJ.
Implications of recent clinical trials for the national cholesterol education program adult treatment panel III guidelines. J Am Coll Cardiol. 2004; 44(3):720-32.

19. Pärssinen M, Seppälä T. Steroid use and long-term health risks in former athletes. Sports Med. 2002; 32(2):83-94.

20. Santora LJ, Marin J, Vangrow J, Minegar C, Robinson M, Mora J, Frieds $G$. Coronary calcification in body builders using anabolic steroids. Preventive cardiology. 2006; 9(4):198-201.

21. Reyes-Fuentes A, Veldhuis JD. Neuroendocrine physiology of the normal male gonadal axis. Endocrinol Metab Clin North Am. 1993; 22(1):93-124.

22. Kafrouni MI, Anders RA, Verma S. Hepatotoxicity associated with dietary supplements containing anabolic steroids. Clin Gastroenterol Hepatol. 2007; 5(7):809-12.

23. Roberts JT, Essenhigh DM. Adenocarcinoma of prostate in 40-year-old body-builder. Lancet. 1986; 328(8509):742.

24. Annitto WJ, Layman WA. Anabolic steroids and acute schizophrenic episode. J clin Psychiatry. 1980; 1(4): 143-144.

25. Freinhar JP, Alvarez W. Androgen-induced hypomania. J clin Psychiatry. 1985; 46(8):354.

26. Brower KJ, Blow FC, Eliopulos GA, Beresford TP. Anabolic androgenic steroids and suicide. Am $J$ Psychiatry. 1989; 146(8):1075.

27. Council for International Organizations of Medical Sciences. International ethical guidelines for biomedical research involving human subjects. Bull Med Ethics. 2002; (182):17-23. 